\title{
Peningkatan Sifat Mekanis Permukaan Master Link Dozer Komatsu Dengan IQT (Induction Quenching Tempering)
}

\author{
Gian Oktaputra Gunawan ${ }^{1, a)}$, Dwita Suastiyanti ${ }^{2, b)}$ dan Pathya Rupajati ${ }^{3, c}$ \\ 1,2,3) Program Studi Teknik Mesin ITI, \\ Jl. Raya Puspiptek Serpong, Tanggerang Selatan-Banten, Indonesia, 15320
}

a)gianoktaputragunawan2@gmail.com, b) dwita_suastiyanti@iti.ac.id, ${ }^{c}$ pathya.rupajati@iti.ac.id

\begin{abstract}
Abstrak
Baja SMnB3H-1 merupakan baja paduan rendah yang banyak digunakan sebagai material komponen mesin seperti master link pada undercarriage yang pada penggunaannya banyak mengalami gesekan atau aus. Master Link adalah salah satu komponen undercarriage bulldozer berfungsi untuk menghubungkan dan memutuskan proses assembly dan diassembly pada track link undercarriage. Untuk meningkatkan ketahanan aus pada master link, diperlukan perlakuan pengerasan permukaan salah satunya yaitu Induction Quenching Tempering (IQT). IQT adalah proses pengerasan baja menggunakan induksi dan dilanjut dengan pendinginan cepat (quenching) menggunakan soluble/polymer. Dalam penelitian ini dilakukan proses IQT dengan variasi holding time 45 detik, 60 detik dan 75 detik pada suhu austenite $\left(850^{\circ}\right)$. Tujuan penelitian ini adalah untuk mengetahui pengaruh holding time IQT terhadap kekerasan dan kekerasan kedalaman (Case Depth). Hasil dari uji kekerasan dan pengukuran case depth didapat nilai tertinggi yaitu pada holding time 75 detik, untuk nilai kekerasan 58,5 HRC sedangkan case depth posisi H1, H2 dan T adalah 31,62 mm, 30,12 mm dan 19,8 mm.
\end{abstract}

Kata Kunci: baja SMnB3H-1, undercarriage, master link, IQT, holding time, case depth

\begin{abstract}
SMnB3H-1 steel is a low alloy steel that is widely used as a material for machine components such as the master link on undercarriage which has a lot of friction or wear. Master Link is one of the components of the bulldozer undercarriage that functions to connect and disconnect the assembly and assembly process on the undercarriage track link. To increase the wear resistance of the master link, one of the hardening treatments needed is Induction Quenching Tempering (IQT). IQT is a steel hardening process using induction and followed by rapid cooling (quenching) using soluble / polymer. In this research, the IQT process with a holding time variation of 45 seconds, 60 seconds and 75 seconds at austenite temperature $\left(850^{\circ}\right)$. The purpose of this study was to determine the effect of IQT holding time on hardness and case depth. The results of the hardness test and case depth measurements obtained the highest value at 75 seconds holding time, for the hardness value of $58.5 \mathrm{HRC}$ while the case depth of H1, H2 and T positions were $31.62 \mathrm{~mm}, 30.12 \mathrm{~mm}$ and $19.8 \mathrm{~mm}$.
\end{abstract}

Keyword: SMnB3H-1 steel, undercarriage, master link, IQT, holding time, case depth

\section{PENDAHULUAN}

Melihat perkembangan teknologi khususnya di bidang industri alat berat maka pengembangan dan inovasi komponen alat berat makin bertambah. Salah satu alat berat yang sering digunakan di lingkungan perhutanan (foresty) adalah bulldozer. Bulldozer adalah sebuah traktor tanah (crawler tractor) yang berfungsi untuk melakukan pekerjaan menggusur dan mendorong tanah. Pada bulldozer terdapat bagian undercarriage. Undercarriage merupakan bagian bawah, dimana komponen tersebut berfungsi sebagai media penggerak. Komponen utama undercarriage terdiri dari track link dan master link, track shoe, track roller, carrier roller dan front idler. Terdapat salah satu komponen penting pada undercarriage, yaitu master link. Master Link berfungsi untuk menghubungkan dan memutuskan proses assembly dan diassembly pada track link. Master link pada umumnya dibuat dari baja paduan rendah (low alloy steel). Pemilihan baja paduan rendah untuk pembuatan master link dikarenakan baja paduan ini memiliki keunggulan secara ekonomis. Salah satunya baja $\mathrm{SMnBH}-1$, untuk mencegah kegagalan master link dilakukan surface hardening guna mendapatkan karakteristik keras di permukaan namun ulet dan tahan aus yang optimal [1].

Di dunia industri alat barat, komponen-komponen mesin alat barat yang paling utama untuk dilakukan proses surface hardening guna untuk meningkatkan kekerasan dan tahan aus yang lebih baik pada bagian - bagian yang bergerak/meluncur dan saling bergesekan satu dengan lainnya. Teknik modifikasi permukaan menggunakaan induksi sangatlah mudah dilakukan dan terbukti dapat menambah kekerasan dengan ketebalan yang diinginkan [2].

Surface hardening merupakan usaha untuk meningkatkan kualitas permukaan suatu baja/material sesuai yang diinginkan. Pengerasan permukaan dilakukan 2 cara yaitu seluruh permukaan dikeraskan atau sebagian saja dari permukaan yang dikeraskan. Pengerasan 
permukaan pada baja meliputi dua jenis yaitu induksi dan Thermo Chemical Treatment, cara induksi seperti IQT (Induction Quenching Tempering) sedangkan cara Thermo Chemical Treatment adalah nitridasi, karburasi dan karbonitridasi [3].

Salah satu metode yang terus berkembang adalah pengerasan permukaan induksi dengan pendinginan cepat (Induction Quenching Tempering). Induction Quenching Tempering ini adalah metode pengerasan permukaan memanfaatkan pemanasan dari sifat listrik, dimana jika suatu baja berada disekitar kumparan coil yang dialiri listrik, akan menyebabkan timbulnya medan magnet yang dapat membuat baja terdapat arus induksi (eddy current), arus induksi tersebut yang dapat memanaskan material. Proses pemanasan dilakukan sampai temperatur Austenite $\left(723 \sim 1250^{\circ} \mathrm{C}\right)$ diikuti dengan pendinginan yang cepat (quenching) pada media soluble/polymer sehingga didapat struktur baja martensit. Tujuan dari quenching adalah meningkatkan kekerasan material agar tahan aus dengan mendapatkan struktur martensit yang keras. Sedangkan proses tempering merupakan perlakuan panas yang dilakukan dengan memanaskan baja pada temperatur di bawah $723^{\circ} \mathrm{C}$ (Austenit) dan ditahan hingga waktu tertentu. Tujuan tempering adalah menurunkan internal stress dan menaikkan kekuatan/keuletan dan ketangguhan [4]

Dalam penelitian ini dilakukan analisa peningkatan sifat mekanis permukaan menggunakan Induction Quenching Tempering dengan variasi waktu tahan (holding time, 45 detik, 60 detik dan 75 detik) terhadap kekerasan dan case depth baja SMnB3H-1 pada permukaan master link. Uji kekerasan dilakukan dengan menggunakan metode Rockwell pada material tanpa Induction Quenching Tempering dan yang telah dilakukan Induction Quenching Tempering untuk menganalisa efek dari Induction Quenching Tempering. Pengukuran kedalaman kekerasan (case depth) dilakukan dengan menggunakan mistar baja untuk mengetahui berapa panjang kedalaman kekerasannya yang telah dilakukan Induction Quenching Tempering.

\section{LANDASAN TEORI}

\section{A. Undercarriage}

Komponen undercarriage pada bulldozer merupakan komponen yang sangat penting, karena undercarriage merupakan komponen untuk menggerakan suatu bulldozer untuk bergerak maju mundur dan belok kanan kiri. Pada undercarriage ada beberapa komponen - komponen penting lainnya seperti ditunjukan pada Gambar 1 .

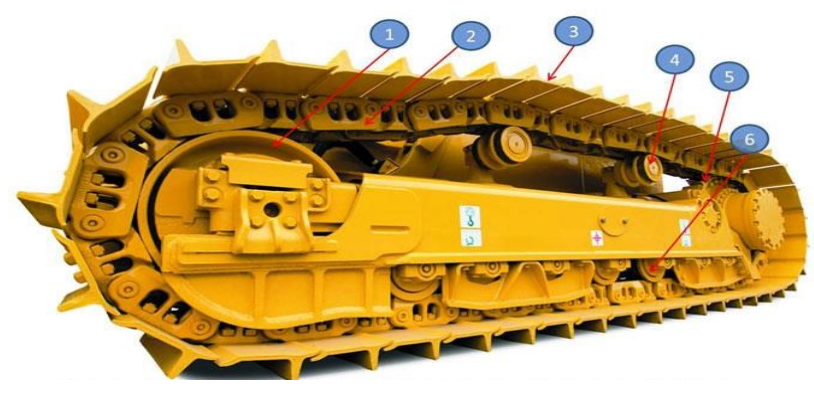

Gambar 1. Undercarriage pada bulldozer
Pada Gambar 1 Undercarriage memiliki komponen utama, yaitu terdiri dari Front Idler, Track link, Track shoe, Carrier Roller, Sprocket/Teeth dan Track Roller.

\section{Front Idler}

Front idler berfungsi untuk membantu mengencangkan atau mengendorkan track link dan juga meredam kejutan. Fron Idler dapat dilihat pada Gambar 2.

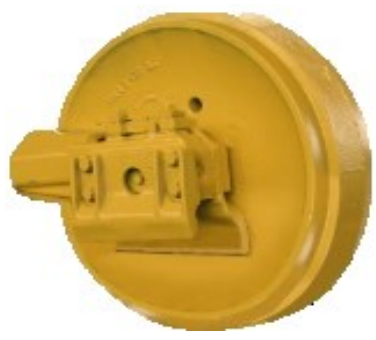

Gambar 2. Front idler

\section{Track Link}

Track link pada unit bulldozer memiliki fungsi sebagai penumpu dari total beban pada track roller sehingga memungkinkan bulldozer dapat berjalan. Track Link dapat dilihat pada Gambar 3.

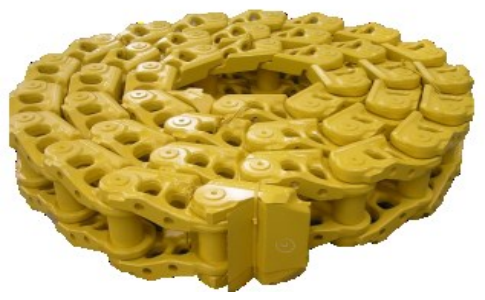

Gambar 3. Track link

\section{Track Shoe}

Track shoe adalah bagian dari undercarriage yang berfungsi disamping tempat persinggungan dengan tanah juga merupakan alas gerak Bulldozer dan Excavator. Track Shoe dapat dilihat pada Gambar 4.

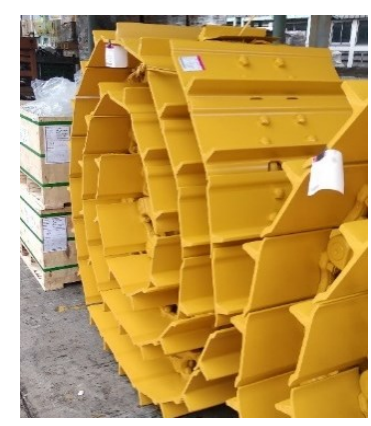

Gambar 4. Track shoe

\section{Roller}

Pada undercarriage terdapat komponen berupa roller yang terbagi menjadi track roller dan carrier roller. Track roller memiliki fungsi untuk membagi berat unit ke track dan sebagai pengarah track link. Sedangkan 
carrier roller merupakan komponen yang berfungsi sebagai penahan gulungan track shoe agar tidak melentur ke bawah dan menjaga kelurusan antara track shoe dengan idler. Roller dapat dilihat pada Gambar 5.

Gambar 5. Carrier roller

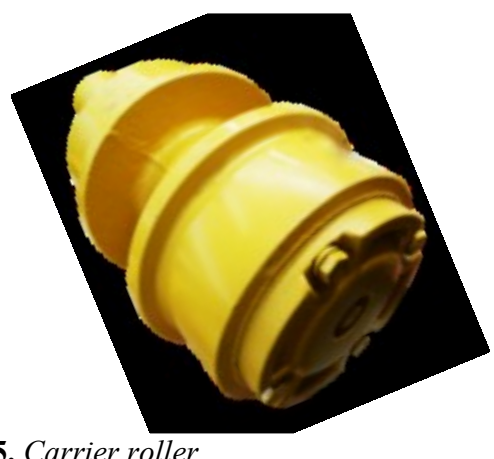

5. Track Roller

Track roller adalah bagian dari komponen undercarriage yang berbentuk menyerupai roda besi yang berfungsi sebagai pembagi berat bulldozer dan excavator ke track. Track Roller dapat dilihat pada Gambar 6.

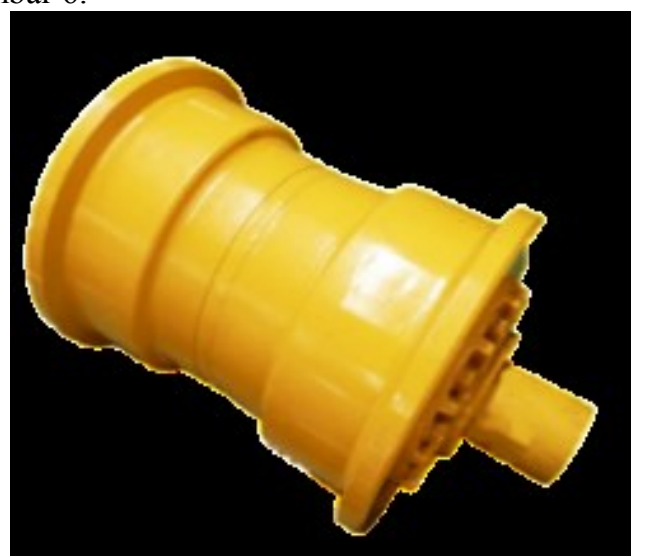

Gambar 6. Track roller

6. Sprocket dan Teeth

Sprocket dan teeth dalam komponen undercarriage adalah sebagai media penerus tenaga gerak ke track melalui bushing, dan merubah putaran sprocket/teeth menjadi gulungan pada track agar unit dapat bergerak. Teeth dapat dilihat pada gambar 7 .

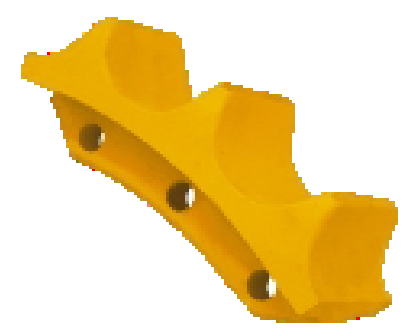

Gambar 7. Segment teeth

Pada Gambar 7. Sprocket pada undercarriage ada dua macam, yaitu solid sprocket dan segment teeth. Sprocket dengan tipe solid sprocket terbuat dari case steel yang merupakan satu kesatuan, sehingga jika ada salah satu teeth pada sprocket yang mengalami kerusakan, maka untuk menggantinya harus dilakukan pemotongan dan dilas kembali. Pada segment teeth bentuknya perbagiannya ada 3 teeth mempermudah mekanik dalam melakukan penggantian, tidak perlu melepas track link pada saat mengalami kerusakan.

\section{B. Master Link}

Terdapat salah satu komponen penting pada undercarriage, yaitu master link. Master Link berfungsi untuk menghubungkan dan memutuskan proses assembly dan diassembly pada track link seperti ditunjukan pada Gambar 8.

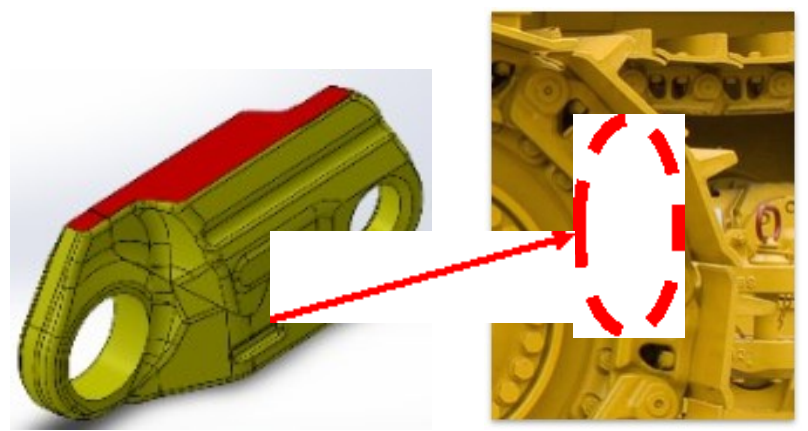

Gambar 8. Master link pada bulldozer

Pada Gambar 8 Terjadinya keausan pada Master Link akibat bergesekan dengan track roller, Carrier roller dan juga idler. Maka dari Struktur pada Master Link dibagian permukaannya diproses perlakuan panas (heat treatment) yang tujuannya agar didapatkan bahan dengan kekerasan tertentu sehingga proses keausan karena gesekan terjadi lebih lama.

\section{Baja}

Baja paling banyak digunakan sebagai bahan industri yang merupakan sumber sangat besar, dimana sebagian ditentukan oleh nilai ekonominya, tetapi yang paling penting karena sifat-sifatnya bervariasi. Yaitu bahan tersebut mempunyai berbagai sifat dari yang paling lunak dan mudah dibuat sampai paling keras. Baja diklasifikasikan bedasarkan komposisi kimianya:

1. Baja Karbon

Baja karbon memiliki 2 unsur, yaitu unsur besi dan baja. Pada umumnya sebagian besar baja hanya mengandung karbon dengan sedikit unsur paduan lainnya. Kandungan karbon dengan persentase yang berbeda dalam campuran logam baja menjadi salah satu pengklasifikasian baja.

- $\quad$ Baja Karbon Rendah (Low Carbon Steel)

Baja karbon rendah adalah baja yang mengandung karbon kurang dari 0,3\%C. Baja karbon rendah merupakan baja yang paling mudah diproduksi diantara karbon yang lain, mudah di machining dan dilas, serta keuletan dan ketangguhannya sangat tinggi tetapi kekerasannya rendah dan tahan aus. Sehingga pada penggunaannya, baja jenis ini dapat digunakan sebagai bahan8 baku untuk pembuatan komponen bodi mobil, struktur 
bangunan, pipa gedung, jembatan, kaleng, pagar, dan lain-lain.

- Baja Karbon Menengah (Medium Carbon Steel) Baja karbon menengah adalah baja yang mengandung karbon $0,3 \% \mathrm{C}-0,6 \% \mathrm{C}$. Baja karbon menengah memiliki kelebihan jika dibandingkan dengan baja karbon rendah yaitu kekerasannya lebih tinggi daripada baja karbon rendah, kekuatan tarik dan batas regang yang tinggi, tidak mudah dibentuk oleh mesin, lebih sulit dilakukan untuk pengelasan, dan dapat dikeraskan dengan baik. Baja karbon menengah banyak digunakan untuk poros, rel kereta api, roda gigi, pegas, baut, komponen mesin yang membutuhkan kekuatan tinggi, dan lain - lain

- Baja Karbon Tinggi (High Carbon Steel)

Baja karbon tinggi adalah baja yang mengandung kandungan karbon $0,6 \% \mathrm{C} 1,7 \% \mathrm{C}$ dan memiliki tahan panas yang tinggi, kekerasan tinggi, namun keuletannya lebih rendah. Baja karbon tinggi mempunyai kuat tarik paling tinggi dan banyak digunakan untuk material perkakas (tools). Salah satu aplikasi dari baja ini adalah dalam pembuatan kawat baja dan kabel baja. Berdasarkan jumlah karbon yang terkandung di dalam baja maka baja karbon ini banyak digunakan dalam pembuatan pegas dan alat-alat perkakas seperti palu, gergaji atau pahat potong. Selain itu, baja jenis ini banyak digunakan untuk keperluan industri lain seperti pembuatan kikir, pisau cukur, mata gergaji, dan sebagainya.

2. Baja Paduan (Alloy Steel)

Baja paduan adalah baja cor yang ditambah unsurunsur paduan. Tujuan dari pemberian unsur-unsur paduan seperti mangan, nikel atau molibden, khrom untuk memberikan sifat-sifat ketahanan aus, ketahanan asam dan korosi atau menambah ketangguhan/thougness.

Baja paduan terdiri dari:

- Baja Paduan Rendah (Low Alloy Steel)

Baja paduan rendah merupakan baja paduan yang elemen paduannya kurang dari $2,5 \% \mathrm{wt}$, misalnya unsur $\mathrm{Cr}, \mathrm{Mn}, \mathrm{Ni}, \mathrm{S}, \mathrm{Si}, \mathrm{P}$ dan lainlain.

- Baja Paduan Menengah (Medium Alloy Steel) Baja paduan menengah merupakan baja paduan yang elemen paduannya 2,5\%-10\% wt, misalnya unsur $\mathrm{Cr}, \mathrm{Mn}, \mathrm{Ni}, \mathrm{S}, \mathrm{Si}, \mathrm{P}$ dan lainlain.

- Baja Paduan Tinggi (High Alloy Steel) Baja paduan tinggi merupakan baja paduan yang elemen paduannya lebih dari $10 \%$ wt, misalnya unsur $\mathrm{Cr}, \mathrm{Mn}, \mathrm{Ni}, \mathrm{S}, \mathrm{Si}, \mathrm{P}$ dan lainlain.

\section{Baja $\mathrm{SMnB} 3 \mathrm{H}-1$}

Baja yang digunakan pada master link adalah baja SMnB3H-1. Baja tersebut adalah material khusus produk
Komatsu untuk komponen master link. Komposisi kimia SMnB3H-1 ditunjukan pada Tabel 1.

Tabel 1. Kandungan unsur baja SMnB3H-1 (material certification komatsu)

\begin{tabular}{cc}
\hline Komposisi Kimia & $\begin{array}{c}\text { Spesifikasi Baja } \\
\text { SMnB3H-1 }\end{array}$ \\
\hline C (\%) & $0,39-0,41$ \\
Si (\%) & $0,15-0,41$ \\
Mn (\%) & $1,30-1,70$ \\
P (\%) & 0,03 \\
S (\%) & 0,03 \\
Ni (\%) & 0,7 \\
Cr (\%) & 0,35 \\
\hline
\end{tabular}

Pada Tabel 1 baja SMnB3H-1 merupakan baja paduan yang mempunyai kandungan mangan cukup tinggi.

\section{E. Perlakuan Panas (Heat Treatment)}

Proses perlakuan panas pada umumnya untuk memodifikasi struktur mikro baja sehingga meningkatkan sifat mekanik, salah satunya yaitu kekerasan. Perlakuan panas didefinisikan sebagai kombinasi dari proses pemanasan dan pendinginan dengan kecepatan tertentu yang dilakukan terhadap logam/paduan dalam keadaan padat, sebagai upaya untuk memperoleh sifat-sifat tertentu. Perubahan sifat tersebut terjadi karena ada perubahan struktur mikro selama proses pemanasan dan pendinginan dimana sifat logam atau paduan sangat dipengaruhi oleh struktur mikro. Proses perlakuan panas terdiri dari beberapa tahapan, dimulai dari proses pemanasan bahan hingga pada suhu tertentu dan selanjutnya didinginkan juga dengan cara tertentu.

Tujuan dari perlakuan panas adalah mendapatkan sifat-sifat mekanik yang lebih baik dan sesuai dengan yang diinginkan seperti meningkatkan kekuatan dan kekerasan, mengurangi tegangan, melunakkan, mengembalikan pada kondisi nomal akibat pengaruh pada pengerjaan sebelumnya, dan menghaluskan butir kristal yang akan berpengaruh pada pengerjaan sebelumnya, dan menghaluskan butir kristal yang akan berpengaruh pada keuletan bahan [5].

\section{F. IQT (Induction Quenching Tempering)}

Secara umum, yang membedakan antara proses IQT dengan proses heat treatment yang lain adalah media untuk memanaskan. IQT merupakan salah satu metode Induction Hardening. Pada proses IQT, pemanasan memanfaatkan sifat listrik, dimana jika suatu baja berada disekitar kumparan coil yang dialiri listrik, akan menyebabkan timbulnya medan magnet yang dapat membuat baja terdapat arus induksi (arus eddy). Arus induksi tersebut yang dapat memanaskan material. Untuk lebih jelasnya dapat dilihat pada Gambar 9. 

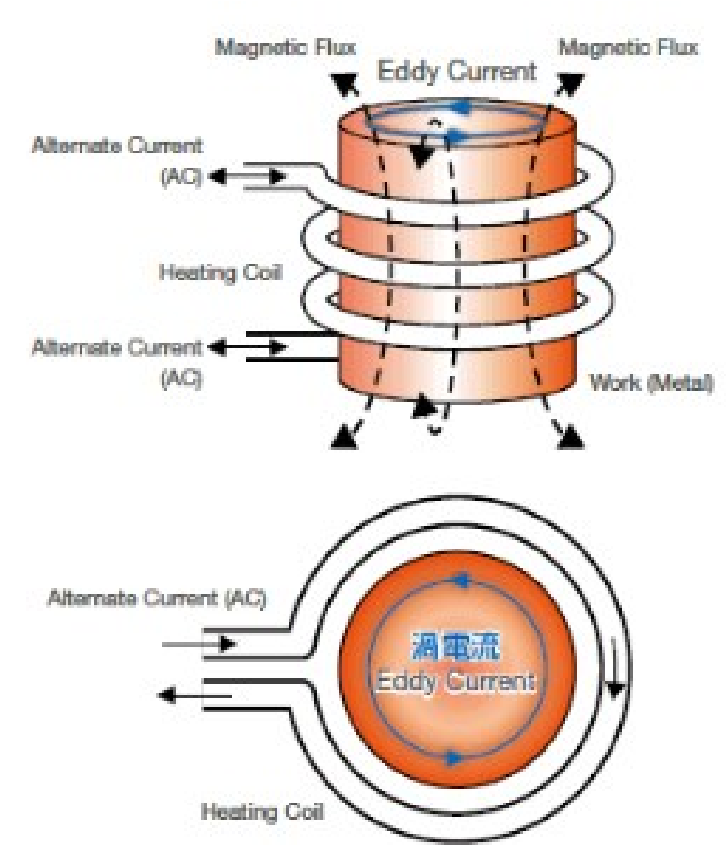

Gambar 9. Arus induksi (eddy current)

Pada Gambar 9. eddy current merupakan arus listrik yang diinduksikan ke dalam konduktor dengan mengubah medan magnet konduktor tersebut. Sirkulasi pusaran arus ini memiliki induktansi dan medan magnet. Medan ini dapat menyebabkan tolakan, tarikan, dorongan, dan efek pemanasan.

Eddy Current terbentuk ketika terjadi perubahan letak konduktor dalam sebuah medan magnet. Konduktor yang bergerak dalam sebuah medan magnet yang tetap ataupun medan magnet yang berubah di sekitar konduktor yang diam, keduanya menyebabkan arus induksi terbentuk dalam konduktor tersebut. Eddy current menghasilkan losses resistif yang dapat mengubah beberapa bentuk energi, seperti energi kinetik menjadi panas.

\section{G. Quenching}

Quenching (celup cepat) adalah pendinginan yang sangat cepat, setelah mengalami perlakuan panas baja langsung didinginkan secara cepat dengan cara dicelupkan ke dalam media pendingin air atau oli. Quenching ini bertujuan untuk mendapatkan martensit. Martensit sifatnya sangat keras. Pada baja karbon rendah dan baja karbon sedang biasanya digunakan media air, sedangkan untuk baja karbon tinggi dan baja paduan biasanya digunakan media minyak. Air lebih cepat mendinginkan bila dibandingkan dengan minyak. Proses pemanasan dilakukan sampai temperatur Austenite $\left(723 \sim 1250^{\circ} \mathrm{C}\right)$. untuk lebih jelasnya dapat dilihat pada Gambar 10 .

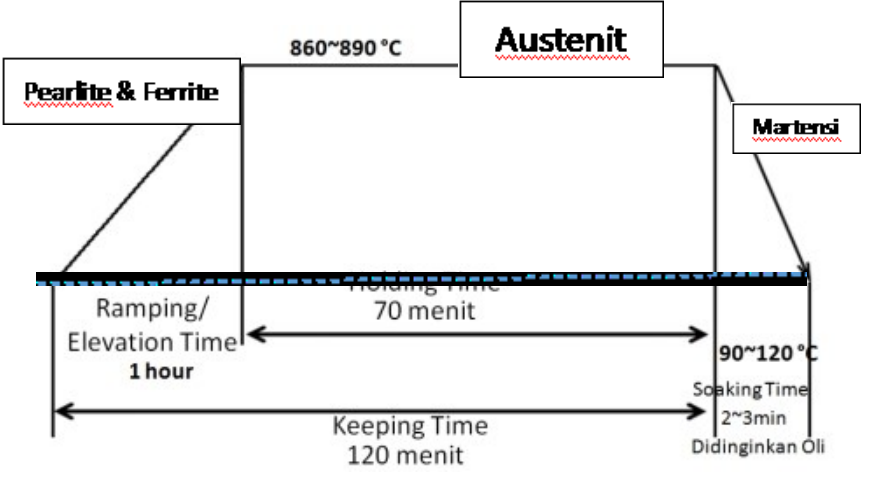

Gambar 10. Laju pendinginan proses quenching

Proses quenching menghasilkan fasa yang keras yang umumnya menghasilkan fasa bainit atau jika laju pendinginannya lebih cepat lagi akan dihasilkan martensit, jika yang terbentuk martensit maka sifatnya sangat keras dan rapuh. Untuk mengurangi kegetasannya maka dilakukan proses temper.

\section{H. Diagram $\mathrm{Fe}-\mathrm{Fe} 3 \mathrm{C}$}

Diagram fasa $\mathrm{Fe}-\mathrm{Fe} 3 \mathrm{C}$ merupakan diagram yang menjelaskan mengenai perubahan fasa seperti ditunjukan pada Gambar 11 .

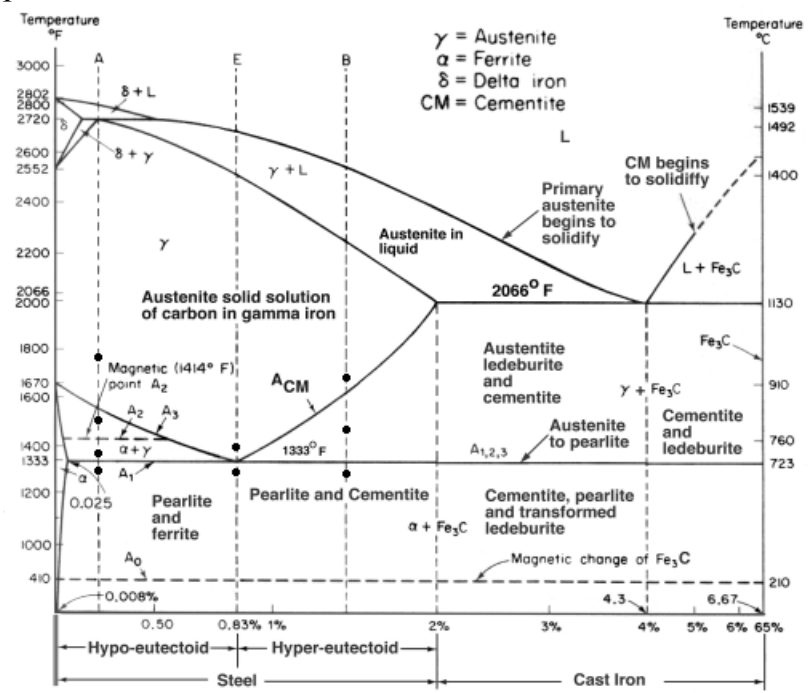

Gambar 11. Diagram fasa Fe-Fe3C (ASM Handbook Vol.4:4, 1991)

Pada Gambar 11 beberapa istilah dalam diagram fasa Fe$\mathrm{Fe} 3 \mathrm{C}$ dan fasa-fasa yang terdapat di dalam diagram akan dijelaskan di bawah ini. Berikut adalah batas-batas temperatur kritis pada diagram $\mathrm{Fe}-\mathrm{Fe} 3 \mathrm{C}$ [6]

1. A1 adalah temperatur reaksi eutectoid yang perubahan fasa $\gamma$ menjadi $\alpha+\mathrm{Fe} 3 \mathrm{C}$ pearlite untuk baja hypoeutectoid.

2. A2 adalah titik Currie (pada temperatur 769 derajat celcius), dimana sifat magnetik besi berubah dari feromagnetik menjadi paramagnetic.

3. A3 adalah temperatur dari fasa $\gamma$ menjadi $\alpha$ (ferrit) yang ditandai pula dengan naiknya batas kelarutan karbon seiring dengan menurunnya temperatur.

4. Acm adalah temperatur tranformasi $\gamma$ menjadi Fe3C cementite yang ditandai pula dengan 
penurunan batas kelarutan karbon seiring dengan menurunnya temperatur.

5. A123 adalah temperatur transformasi $\gamma$ menjadi $\alpha+$ Fe3C pearlite untuk baja hypereutectoid

\section{Tempering}

Baja yang telah di quenching bersifat rapuh dan kurang cocok digunakan. Melalui tempering, kekerasan dan kerapuhan dapat diturunkan sampai memenuhi syarat penggunaan. Proses tempering terdiri dari pemanasan kembali baja yang telah dipanaskan atau dikeraskan pada suhu dibawah $723^{\circ} \mathrm{C}$ (austenite) disusul dengan pendinginan. Meskipun proses ini menghasilkan baja yang lunak, proses ini berbeda dengan proses anil karena disini sifat-sifat dapat dikendalikan dengan cermat. Untuk lebih jelasnya dapat dilihat pada Gambar 12.

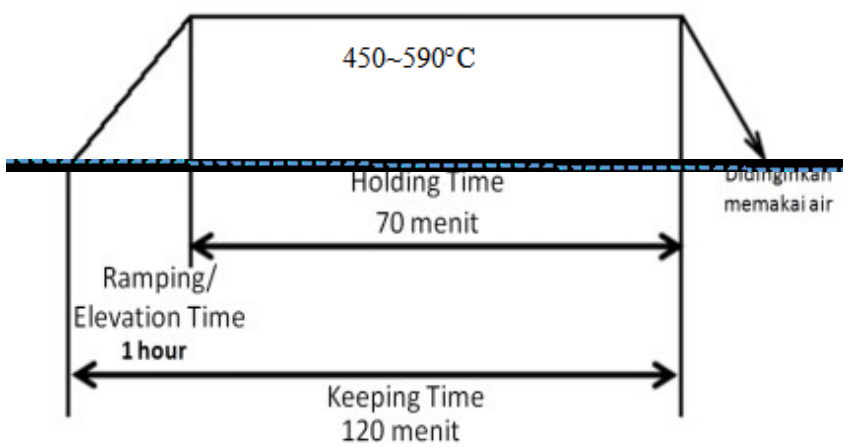

Gambar 12. Laju pendinginan proses tempering

Proses tempering sangat bergantung pada temperatur temper, ditinjau dari aspek capaian kekerasannya temperatur temper dibagi menjadi 3 kelompok sebagai berikut;

- Temperatur temper tahap I, dilakukan pada temperatur $80-200^{\circ} \mathrm{C}$. pada tahap ini terjadi transformasi fasa martensit menjadi martensit temper dan karbida epsilon $\left(\mathrm{Fe}_{2,4} \mathrm{C}\right)$, dan jika terdapat austenit sisa maka austenit sisa tersebut akan bertransformasi menjadi martensit.

- Temperatur temper tahap II, dilakukan pada temperatur $200-400^{\circ} \mathrm{C}$. pada tahap ini terjadi transformasi martensit menjadi $\alpha+\mathrm{Fe}_{3} \mathrm{C}$, dan jika masih terdapat austenit sisa maka akan bertransformasi juga menjadi $\alpha+\mathrm{Fe}_{3} \mathrm{C} . \alpha+\mathrm{Fe}_{3} \mathrm{C}$ disini memiliki bentuk sementit yang lamellar (serpih)

- Temperatur temper tahap III, dilakukan pada temperatur $400-600^{\circ} \mathrm{C}$, pada tahap ini transformasi yang terjadi adalah seperti pada temperatur temper tahap II, hanya saja pada $\alpha+\mathrm{Fe}_{3} \mathrm{C}$ yang terbentuk memiliki bentuk sementit yang globular (bulat).

\section{J. Jenis - Jenis Media Quenching}

1. AIR

Air adalah media quenching yang paling sering digunakan dalam proses quenching. Air murni atau aquades memiliki kapasitas pendinginan yang sangat besar pada temperatur $300^{\circ} \mathrm{C}$, temperatur dimana pada kebanyakan baja formasi martensite mulai terbentuk. Hal ini akan mempengaruhi tegangan yang terjadi saat transformasi, sehingga akan meningkatkan resiko terjadinya crack.

Bahaya dari crack yang terjadi selama proses quenching pada media air dapat dikurangi dengan cara mengeluarkan baja saat temperaturnya 200$400^{\circ} \mathrm{C}$, kemudian diquenching pada media oli. Cara ini juga akan meningkatkan kedalaman kekerasan pada baja paduan rendah.

2. OLI

Kapasitas pendinginan oli lebih kecil dari pada air. Ada berbagai macam jenis oli yang bisa dijadikan media quenching. Spindle oil adalah oli mineral standar yang paling mudah didapat dan harganya murah. Pada umumnya, oli memiliki kapasitas pendinginan tertinggi pada temperatur $600^{\circ} \mathrm{C}$, dan agak rendah pada temperatur pembentukan martensite. Karena oli mempunyai kapasitas pendinginan yang lebih lambat dari air, maka oli sering digunakan untuk baja paduan rendah sampai medium, dengan dimensi yang tidak terlalu besar.

Ada beberapa cara untuk meningkatkan kapasitas pendinginan oli. Pertama, dengan memberikan olakan pada oil bath. Kedua, dengan meningkatkan temperatur oli sampai $50-80^{\circ} \mathrm{C}$. Ketiga, dengan mencampurkan 'water-soluble' oli dan air (emulsions).

\section{POLIMER}

Pencampuran air dan 10\% polimer seperti polyvinyl alcohol (PVA), akan mendapatkan kapasitas pendinginan antara kapasitas pendinginan air dan oli. Keungulan menggunakan polimer adalah mengurangi resiko timbulnya api yang terjadi saat pendinginan pada media oli. Dengan tambahan $2 \%$ polimer pada air, resiko terjadinya crack pada baja non paduan yang di quench dapat dikurangi tanpa kehilangan kekerasan yang diinginkan.

Konsentrasi polimer pada media quenching harus dijaga, karena apabila konsentrasi polimer meningkat akan meningkatkan juga kapasitas pendinginan, yang akan mengakibatkan terjadinya crack. Kadar $\mathrm{pH}$ juga harus dijaga agar diatas 7.5, karena bila $\mathrm{pH}$ dibawah 7.5 akan menimbulkan bahaya korosi pada baja.

\section{K. Pengujian Kekerasan Rockwell}

Pengujian Rockwell mirip dengan pengujian Brinell, yakni angka kekerasan yang diperoleh merupakan fungsi derajat indentasi. Beban dan indentor yang digunakan bervariasi tergantung pada kondisi pengujian. Berbeda dengan pengujian brinell, indentor dan beban yang digunakan lebih kecil sehingga menghasilkan indentasi yang lebih kecil dan lebih halus. Banyak digunakan di industri karena prosedurnya lebih cepat [7]. 
Tabel 2. Tabel skala kekerasan rockwell (ASTM - E 10,2014)

\begin{tabular}{|c|c|c|c|}
\hline SCALE & $\begin{array}{l}\text { MANOR LOAD, } \\
\text { KG }\end{array}$ & $\begin{array}{l}\text { TYPE OF } \\
\text { INDENTER }\end{array}$ & TYPICAL MATERIALS TESTED \\
\hline A & 60 & Diamond cone & $\begin{array}{l}\text { Extremeiy hard materials, tungsten } \\
\text { carbides, etc. }\end{array}$ \\
\hline B & 100 & $y / 10^{*}$ ball & $\begin{array}{l}\text { Medium hard materials, low- and } \\
\text { medium-carbon steels, brass. } \\
\text { bronze, etc. }\end{array}$ \\
\hline c & 150 & Diamond cone & $\begin{array}{l}\text { Hardened steels, hardened and } \\
\text { tempered alloys }\end{array}$ \\
\hline D & 100 & Diamond cone & Case-hardened steel \\
\hline E & 100 & $1 / 0^{*}$ ball & $\begin{array}{l}\text { Cast iron, aluminum and magnesium } \\
\text { alloys }\end{array}$ \\
\hline $\mathbf{F}$ & 60 & $110^{0}$ ball & Annealed brass and copper \\
\hline G & 150 & $1 / 0^{\prime \prime}$ ball & $\begin{array}{l}\text { Beryllium copper, phosphor } \\
\text { bronze, etc. }\end{array}$ \\
\hline H & 60 & $\% \theta^{*}$ ball & Aluminum sheet \\
\hline$\kappa$ & 150 & $1 / e^{-}$ball & Cast iron, aluminum alloys \\
\hline L & 60 & $1 / 4^{-}$ball & Plastics and soft metals such as leac \\
\hline M & 100 & $1 / 4^{-}$ball & Same as L scale \\
\hline P & 150 & $1 / 4$ ball & Same as L scale \\
\hline R & 60 & $1 / 2$ - ball & Same as L scale \\
\hline s & 100 & $1 / 2^{2}$ ball & Same as $L$ scale \\
\hline $\mathrm{v}$ & 150 & $1 / \tau^{*}$ ball & Same as L scale \\
\hline
\end{tabular}

\section{METODE PENELITIAN}

Penelitian dimulai dengan persiapan material master link dan peralatan yang diperlukan yang diikuti dengan tahap-tahap selanjutnya mengacu pada diagram alir seperti ditunjukkan pada Gambar 13.

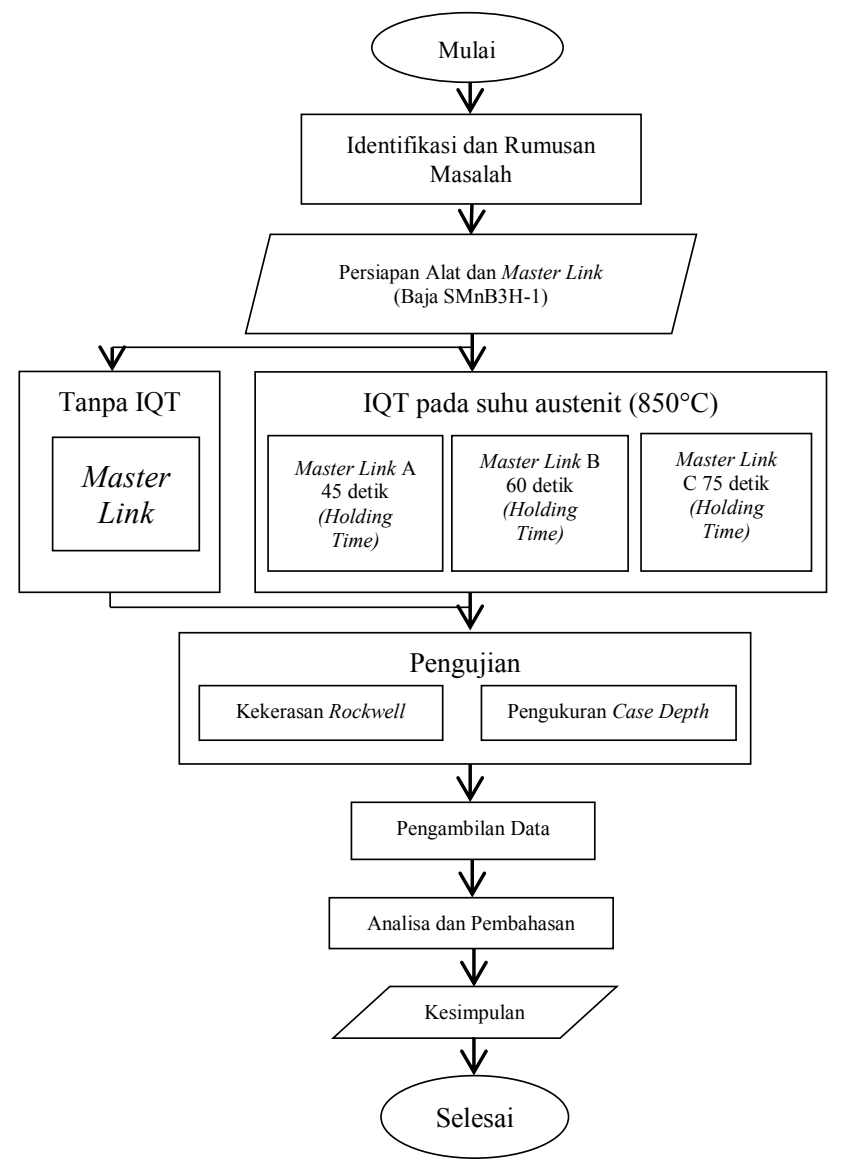

Gambar 13. Diagram alir penelitian

Spesimen/master link untuk proses IQT adalah 4 buah Master Link dengan material baja SMnB3H-1 dengan dimensi lebar 39,35 mm. Dimensi spesimen seperti ditunjukkan pada Gambar 14.

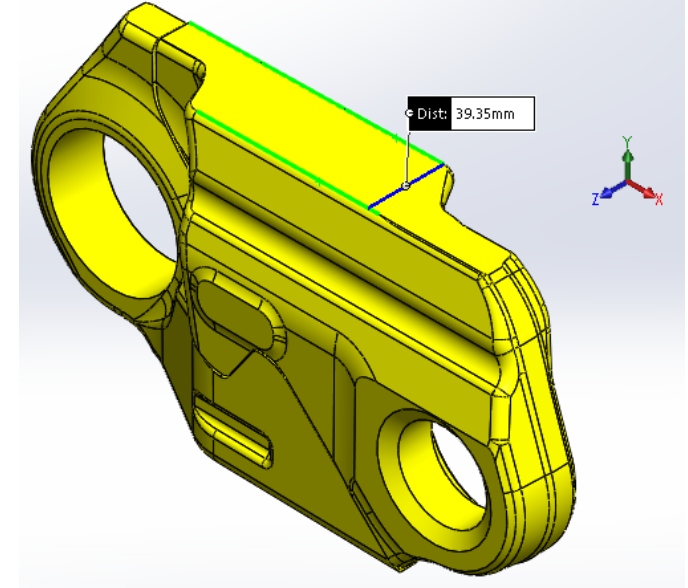

Gambar 14. Dimensi spesimen master link SMnB3H-1

Pengerasan permukaan metode IQT dilakukan pada suhu austenite $\left(850^{\circ} \mathrm{C}\right)$ dengan variasi holding time 45 detik, 60 detik dan 75 detik, pengujian sifat mekanis, yaitu pengujian kekerasan rockwell dan pengukuran kedalaman kekerasan (case depth).

\section{HASIL DAN PEMBAHASAN}

A. Hasil Pengujian Kekerasan Rockwell

Pada pengujian kekerasan roclwell menggunakan 13 titik sampel, beban indentasi sebesar $150 \mathrm{~kg}$, jarak $2 \mathrm{~mm}$ dari permukaan dan waktu pembebanan 9 detik. Pengukuran ini dimulai dari bagian cut piece $1 \mathrm{~s} / \mathrm{d}$ bagian cut piece 5 ditunjukkan pada Gambar 15.

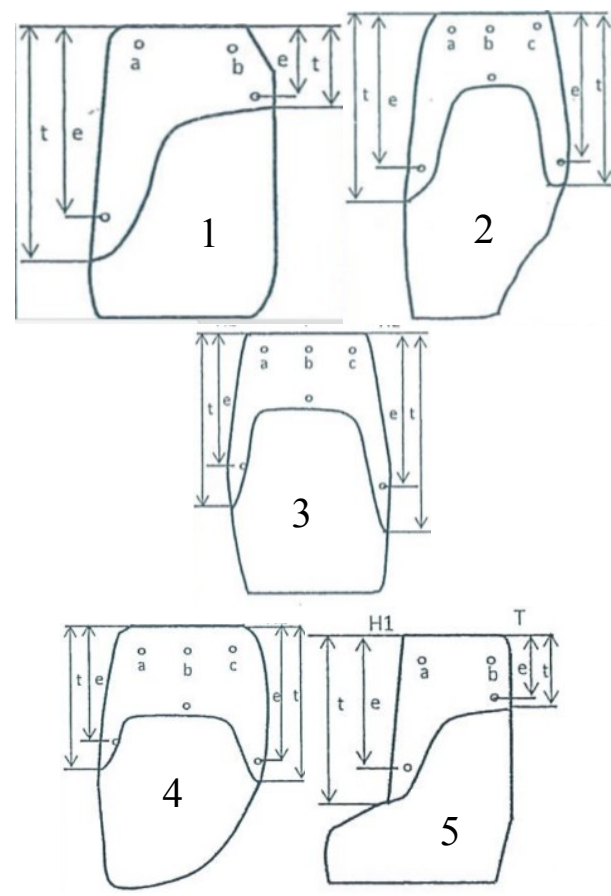

Gambar 15. Titik-titik spesimen pengujian kekerasan

Pada Gambar 15 Bagian cut piece no 1 dan 5 mempunyai 2 titik penekanan. Sedangkan bagian cut piece no 2, 3 dan 4 mempunyai 3 titik penekanan.

Nilai kekerasan setelah IQT dengan variasi holding time 45 detik, 60 detik dan 75 detik pada suhu austenite $\left(850^{\circ} \mathrm{c}\right)$ angka kekerasannya mengalami peningkatan yang 
bervariasi. Hasil rata-rata kekerasan untuk master link sebelum dan sesudah dilakukan metode IQT ditunjukkan pada Tabel 3 .

Tabel 3. Rata-rata kekerasan sebelum dan sesudah IQT

\begin{tabular}{|c|c|c|c|c|}
\hline Metode & $\begin{array}{l}\text { Kode } \\
\text { Master } \\
\text { Link }\end{array}$ & $\begin{array}{c}\text { Waktu } \\
\text { Tahan } \\
\text { (Holding } \\
\text { Time) }\end{array}$ & $\begin{array}{l}\text { Temperatur } \\
\left({ }^{\circ} \mathrm{C}\right)\end{array}$ & $\begin{array}{c}\text { Rata-Rata } \\
\text { Kekerasan } \\
\text { (HRC) }\end{array}$ \\
\hline \multirow{5}{*}{ IQT } & Master & Tanpa & \multirow{2}{*}{ Tanpa IQT } & \multirow{2}{*}{36,8} \\
\hline & Link & IQT & & \\
\hline & A & 45 detik & $850^{\circ} \mathrm{C}$ & 49,23 \\
\hline & B & 60 detik & $850^{\circ} \mathrm{C}$ & 54,96 \\
\hline & $\mathrm{C}$ & 75 detik & $850^{\circ} \mathrm{C}$ & 58,50 \\
\hline
\end{tabular}

Berdasarkan data Tabel 3 untuk memudahkan membaca nilai kekerasannya maka dibuat grafik hubungan antara nilai kekerasan pada Master Link baja SMNB3H-1 sebelum dan sesudah IQT dengan variasi Holding Time ditunjukkan pada Gambar 16.

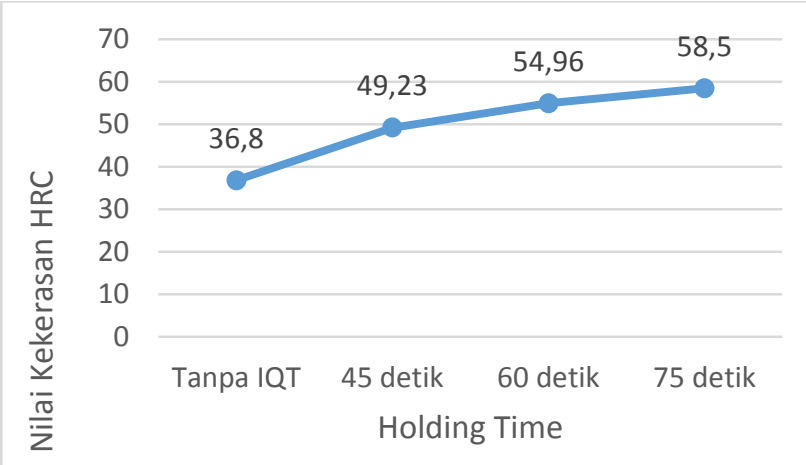

Gambar 16. Grafik hubungan nilai kekerasan terhadap Holding Time.

Pada Gambar 16 terdapat tiga buah master link yang di IQT yang berbeda penahan waktunya (Holding Time) yaitu 45 detik, 60 detik dan 75 detik pada suhu austenite $\left(850^{\circ} \mathrm{C}\right)$. Semua master link yang telah dilakukan IQT didinginkan cepat (quenching) dengan menggunakan soluble/polymer.

Pada master link dengan holding time 45 detik memiliki kekerasan rata-rata kekerasan sebesar 49,23 HRC atau meningkat 33,77 \% terhadap master link tanpa IQT. Nilai kekerasan pada master link dengan holding time 60 detik didapat nilai kekerasan rata-rata sebesar 54,96 HRC meningkat 49,34 \% terhadap master link tanpa IQT. Tingkat kekerasan dengan holding time 75 detik dapat dirata-rata sebesar 58,5 HRC atau meningkat 58,96\% terhadap master link tanpa IQT.

Rata-rata nilai HRC mengalami peningkatan pada setiap variasi holding time, dari nilai tersebut menunjukan bahwa nilai kekerasan meningkat setelah proses IQT. Hal ini disebabkan karena proses IQT pada baja SMnB3H-1 pada suhu austenite $\left(850^{\circ} \mathrm{C}\right)$ dengan variasi holding time yang sebelumnya baja terbentuk struktur ferrit dan perlit yang bersifat lunak dan ulet akan berubah menjadi struktur martensit yang bersifat keras dan getas [8].
Kekerasan maksimum master link yang terbentuk tergantung pada persen (\%) martensit yang terbentuk. Menurut ASM Vol 4: Heat Treating dengan kadar karbon $0,31 \%$, sesuai komposisi kimia master link dianggap membentuk 99\% martensit apabila kekerasannya mencapai 509 BHN atau apabila dikonversikan kedalam nilai kekerasan HRC yaitu sekitar 54 HRC [9]

Menurut KES (Komatsu Engineering Standard) permukaan kekerasan pada master link harus berada pada nilai $51 \mathrm{HRC}$ - 58 HRC. Pada holding time 45 detik nilai kekerasan HRC belum sesuai dengan standard KES. Hal ini disebabkan karena waktu tahan ketika proses pemanasan (Heating) terlalu cepat yang menyebabkan tidak tercapainya struktur austenite. Sedangkan pada holding time 60 detik nilai kekerasan HRC sudah sesuai standard KES karena waktu tahannya yang sesuai menyebabkan terbentuknya struktur austenite ketika proses heating dan ketika dilanjut proses pendinginan cepat akan terbentuk seluruh struktur martensit $99 \%$. Nilai kekerasan HRC yang paling tinggi dihasilkan ada pada waktu tahan (holding time) 75 detik. Nilai kekerasan HRC tersebut tidak sesuai dengan standard KES. Karena apabila nilai kekerasannya tinggi, sifat mekanis permukaan master link menjadi sangat keras dan rapuh. Hal ini disebabkan waktu tahan (holding time) terlalu lambat yang menyebabkan ketika proses heating melebihi dari suhu austenite $\left(850^{\circ} \mathrm{C}\right)$ dan ketika dilanjut pendingingan cepat master link tersebut kekerasannya akan tinggi dan kemungkinan besar juga master link tersebut akan retak (Crack).

Setelah proses IQT menunjukan bahwa baja karbon rendah (Low Alloy Steel) SMnB3H-1 kekerasannya dapat meningkat dan juga memperlihatkan adanya perbedaan peningkatan kekerasan dengan adanya beda variasi holding time yang diterapkan, artinya bertambahnya holding time mempunyai efek untuk meningkatkan kekerasan pada proses pengerasan baja hasil Induction Quenching Tempering.

\section{B. Kedalaman Kekerasan (Case Depth)}

Setelah master link dilakukan proses Induction Quenching Tempering maka master link tersebut akan mempunyai kedalaman kekerasan (Case Depth). Ada beberapa definisi mengenai lapisan hasil Induction Quenching Tempering antara lain:

1. Total Case Depth ( $t$ ) adalah jarak yang diukur tegak lurus terhadap permukaan master link yang telah mengalami proses pengerasan menuju ke inti material dimana ditemukannya kekerasan awal dari material.

2. Effective Case Depth (e) adalah jarak yang diukur tegak lurus terhadap permukaan master link yang telah menjalani proses pengerasan Induction Quenching Tempering ke titik dimana kekerasan yang dicapai adalah 53 HRC.

Ada beberapa posisi pengukuran case depth sesuai standard KES. Yaitu posisi H1, H2 dan T. untuk lebih jelasnya dapat dilihat pada Gambar 17. 


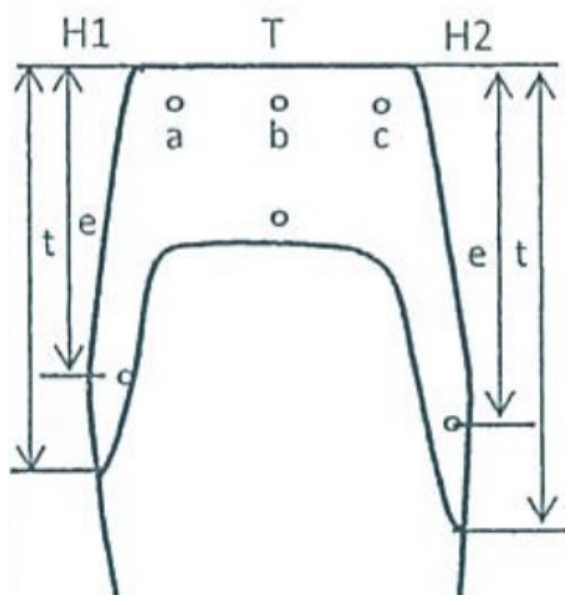

Gambar 17. Posisi case depth sesuai standard KES.

Pada Gambar 17 posisi H1 adalah posisi height atau kedalaman case depth sisi outside atau sisi luar. Sedangkan posisi $\mathrm{H} 2$ adalah posisi height atau kedalaman case depth sisi inside atau sisi dalam. Posisi T adalah posisi kedalaman Center atau tengah.

Standard ukuran case depth pada master link tergantung pada posisi effective case depth nya, untuk posisi $\mathrm{H} 1$ dan $\mathrm{H} 2$ ukuran standard effective case depth nya adalah $19-31 \mathrm{~mm}$. Pada posisi T ada dua posisi standard, untuk posisi $\mathrm{T}$ pada cut piece bagian 1 dan 5 standard KES effective case depth nya adalah $8-16 \mathrm{~mm}$. Sedangkan untuk posisi T pada cut piece bagian 2,3 dan 4 standard KES effective case depth nya adalah $8-13 \mathrm{~mm}$. Apabila case depth nya kurang dari standard KES, maka master link bila digunakan akan cepat aus dari waktu penggunaan (Life Time) pada undercarriage. Sedangkan bila hasil case depth nya melebihi dari standard KES, apabila master link digunakan akan retak. Hal ini disebabkan karena setelah proses IQT dengan holding time yang lambat ketika di heating panasnya akan cepat meluas kedalam master link, yang membuat hilangnya karakterisktik ulet pada material master link [1].

Nilai kedalaman kekerasan (case depth) dengan Holding Time 45 detik, 60 detik dan 75 pada suhu austenite $\left(850^{\circ} \mathrm{C}\right)$ kedalaman kekerasannya (case depth) bervariasi. Hasil rata-rata kedalaman kekerasan (case depth) untuk master link sesudah dilakukan metode Induction Quenching Tempering ditunjukkan pada Tabel 4.
Tabel 4. Rata-rata nilai kedalaman kekerasan (Case Depth)

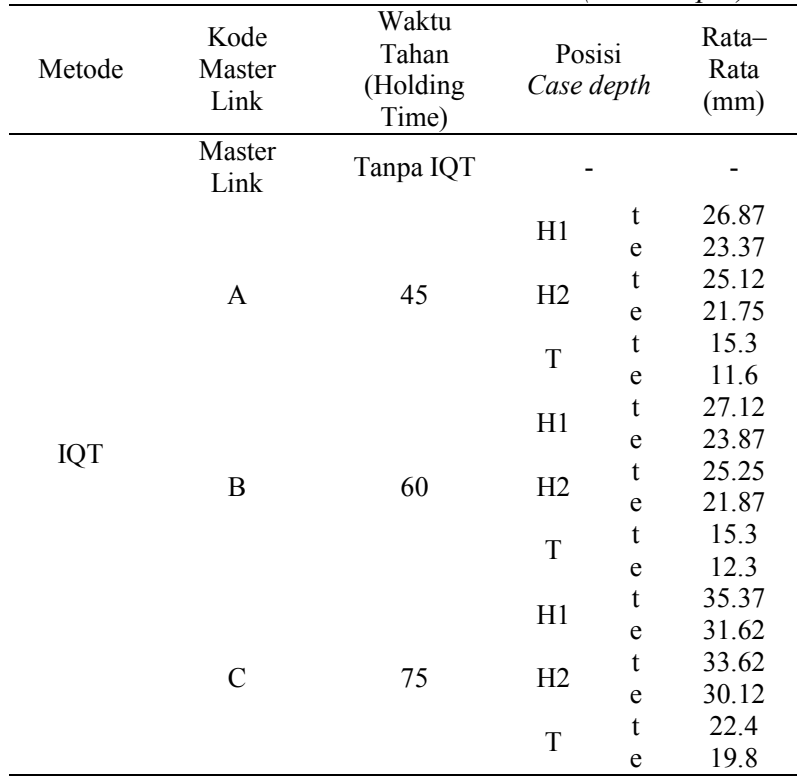

Pada Tabel 4 rata-rata hasil kedalaman kekerasan (Case Depth) pada holding time 45 dan 60 detik hasil case depth nya sudah sesuai standard KES. Tetapi pada holding time 45 detik meskipun hasil case depth nya sesuai standard KES, tetapi hasil rata-rata kekerasan HRC nya belum sesuai standard KES. Hal ini disebabkan karena ketika proses IQT pada holding time 45 detik waktu tahan ketika proses pemanasan (Heating) terlalu cepat yang menyebabkan tidak tercapainya struktur austenite, sehingga ketika dilakukan proses pendinginan cepat (quenching) kekerasan HRC nya masih dibawah rata - rata 51 - 58 HRC. Rata-rata kedalaman kekerasan (Case Depth) pada Holding Time 75 detik hasil case depth nya over atau melebihi standard KES. Hal ini disebabkan waktu tahan ketika proses IQT terlalu lama, sehingga ketika di heating menimbulkan panas berlebih terhahap material master link.

Berdasarkan hasil pengalaman di lapangan master link yang telah diproses IQT dengan Holding Time 45 detik dengan hasil kekerasan 49,23 HRC keausannya akan lebih cepat kerena kekerasan HRC belum 99 \% martensit. Hal ini disebabkan karena kontak langsung master link dengan track roller yang menahan beban keseluruhan Bulldozer. Keausan akan disebabkan oleh partikel - partikel tanah atau pasir keras yang masuk diantara permukaan master link dan permukaan roller seperti ditunjukan pada Gambar 18.

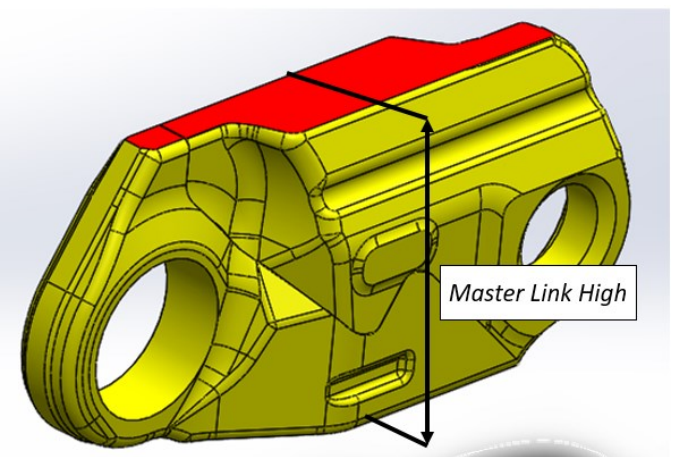

Gambar 18. Keausan permukaan master link 
Pada Gambar 18 keausan seperti ini menyebabkan ukuran Master Link High berkurang, dan kerusakan pada pin boss. Hal ini disebabkan karena ada gesekan secara langsung antara flange dan track roller dengan pin boss [5].

Master Link hasil proses IQT dengan holding time 75 detik tidak dapat digunakan pada undercarriage bulldozer. Hal ini disebabkan karena material dari master link sangat getas dan rapuh. Ketika proses IQT pada holding time 75 detik setelah master link di heating dan dilanjutkan proses quenching material sudah mengalami retak (crack). Hal ini karena material baja SMnB3H-1 yang telah melalui proses quenching akan mengalami keretakan (Crack) karena pengaruh internal stress ataupun tidak tercapainya kekerasan yang diinginkan. Retak pada proses quenching merupakan suatu permasalahan yang sangat mendasar [10].

Dengan Holding Time 60 detik meskipun hasil kekerasan HRC dan kedalaman kekerasan (Case Depth) sudah sesuai dengan Komatsu Engineering Standard (KES). Life Time dari master link terhadap undercarriage tergantung dari cara penggunaan unit bulldozer dan daerah penggunaan unit bulldozer. Apabila unit bulldozer sering digunakan pada daerah yang berbatu dan berpasir, master link tersebut akan cepat aus karena apabila didaerah yang berbatu komponen master link pada undercarriage tersebut akan mengalami banyak kejutan. Sedangkan apabila didaerah yang berpasir, partikel - partikel pasir keras akan masuk pada permukaan master link dan permukaan track roller. Oleh karena itu sifat mekanis pada permukaan master link harus keras pada permukaan namun ulet dan tahan aus yang optimal [1].

\section{KESIMPULAN}

Dari hasil penelitian ini didapat beberapa kesimpulan sebagai berikut:

1. Proses Induction Quenching Tempering (IQT) mempengaruhi bertambahnya sifat mekasnis permukaan baja SMnB3H-1 Master Link. Pada master link sebelum Induction Quenching Tempering (IQT) didapatkan nilai rata-rata 36,8 HRC. Sedangkan pada master link hasil Induction Quenching Tempering (IQT) didapatkan dengan nilai kekerasan HRC tertinggi pada holding time 75 detik dengan nilai kekerasan 58,50 HRC.

2. Diantara Holding Time 45 detik, 60 detik dan 75 detik yang paling baik digunakan menurut kekerasan HRC adalah holding time 60 detik. Pada holding time 60 detik nilai kekerasan HRC sudah sesuai standard KES yaitu dengan rata - rata nilai kekerasan 54,96 HRC karena waktu tahannya yang sesuai menyebabkan terbentuknya struktur austenite ketika proses heating dan ketika dilanjut proses pendinginan cepat (quenching) akan terbentuk seluruh struktur martensit $99 \%$.

3. Kedalaman kekerasan (Case Depth) hasil holding time 60 detik adalah yang paling baik digunakan karena sudah seseuai dengan standard KES. Untuk rata - rata nilai posisi $\mathrm{H} 1$ effective case depth adalah $23,87 \mathrm{~mm}$, posisi rata-rata nilai $\mathrm{H} 2$ effective case depth adalah $21,87 \mathrm{~mm}$ dan untuk rata-rata nilai posisi T effective case depth adalah $12,3 \mathrm{~mm}$.

\section{UCAPAN TERIMA KASIH}

Ucapan terima kasih disampaikan kepada Bapak Tommy Lufthansa, ST. dan Bapak Ade serta Staff dan karyawan PT Komatsu Undercarriage Indonesia utamanya Production Engineering dan Heat Treatment section, atas bantuan dan kerja samanya.

\section{REFERENSI}

[1] Dewa Ngakan Ketut Putra Negara, I Dewa Made Krisnha Muku, Kekerasa Dan Ketahanan Aus Baja Karbon Rendah Setelah Surface Hardening, Prosiding Seminar Nasional Tahunan Teknik Mesin XV (SNTTM XV), 5 - 6 Oktober 2016.

[2] Rifky Ismail, Nizar Rahman Aprilitama, Sugiyanto, Pengamatan Struktur Mikro Dan Kekerasan Pada Roda Gigi Pasca Pengerasan Permukaan Menggunakan Panas Induksi, Rotasi Jurnal Teknik Mesin, Vol. 17, No. 3 Juli 2015: 145 - 152 .

[3] Muhammad Iqbal, Pengaruh Temperatur Terhadap Sifat Mekanis Pada Proses Pengkarbonan Padat Baja Karbon Rendah, Jurnal SMARTek, Vol. 06, No. 2 Mei 2008: 104 112.

[4] Yopi Handoyo, Pengaruh Quenching dan Tempering Pada Baja JIS Grade S45C Terhadap Sifat Mekanis Dan Struktur Mikro Crankshaft, Jurnal Ilmiah Teknik Mesin, Vol. 03, No. 02.

[5] ASM Handbook Vol: 4. 1991. Vol-4 Heat Treating. In ASM Handbook.

[6] Ahmad Yunus Nasution, Muhammad Nur, Pengujian Mesin Press Mekanik Semi Otomatis Dengan Penggerak Motor Listrik 0,5 HP, Jurnal Sintek, Vol. 10, No. 02.

[7] Davis, H.E., Troxell, G.E., Wiskocil, C.T., The Testing and Inspection of Engineering Materias. McGraw-Hill Book Company. New York. USA.

[8] Riyanto, Analisa Perbandingan Materian JIS SCM 415 Dan JIS SCM 420 Pada Proses Heat Treatment, Jurnal Teknik Mesin, Vol. 04, No. 1, Februari 2015

[9] Bayu Adie Septianto, Yuli Setiyorini, Pengaruh Media Pendingin Pada Heat Treatment Terhadap Struktur Mikro Dan Sifat Mekanik Friction Wedge AISI 1340, Jurnal Teknik Pomits, Vol. 2, No. 2.

[10] Eqmond D. Sitompul \& Surya Dharma (2018), Pengaruh Variasi Kosentrasi Media Pendingin (Quenchant) Pada Prose Quench Terhadap Kekerasan, Struktur Mikro Dan Retak Akibat Quench (Quench Crack) Dari Baja AISI 1040, Jurnal Rotor, Vol. 11, No. 1. April 2018. 